\title{
田
}

\section{VIOLÊNCIA, DISCRIMINAÇÃO, RACISMO E CONFLITOS ENVOLVENDO OS POVOS INDÍGENAS DO BAIXO TAPAJÓS}

\author{
VIOLENCE, DISCRIMINATION, RACISM AND CONFLICTS INVOLVING THE INDIGENOUS PEOPLE \\ OF THE REGION OF THE "BAIXO TAPAJÓS”
}

\author{
Solange Maria Gayoso da Costa* \\ http://orcid.org/0000-0002-5542-3663
}

\section{RESUMO}

Neste artigo apresenta-se dados sobre os conflitos vivenciados pelos povos indígenas da região do baixo rio baixo Tapajós no estado do Pará. Através da revisão bibliográfica e observação participante, foi possível identificar que os povos indígenas sofrem casos de ameaças, violências diversas, criminalização e racismo.

\section{PALAVRAS-CHAVE}

Povos Indígenas, Conflitos, Violência, Racismo, Baixo Tapajós.

\begin{abstract}
In this article we present data about the conflicts experienced by the indigenous peoples of the region of the Baixo Tapajós River in the state of Pará. Through bibliographic review and participant observation, it was possible to identify how indigenous peoples suffer from threats, criminalization and racism.
\end{abstract}

\section{KEYWORDS}

Indigenous Peoples, Conflicts, Violence, Racism, Baixo Tapajós.

\section{INTRODUÇÃO}

Os dados sobre violência contra os povos indígenas no Brasil, publicados pelo Conselho Indigenista Missionário (Cimi) nos relatórios intitulados Violência Contra os Povos Indígenas no Brasil, nos últimos anos, evidencia a relação conflituosa existente na sociedade brasileira e seus povos originários, de negação permanente dos direitos dos povos indígenas, principalmente o direito à permanência em seu território.

São inúmeras situações de violência registradas envolvendo casos de assassinatos, espancamentos, ameaças de morte, invasão e devastação das terras demarcadas,

\footnotetext{
* Assistente Social. Doutora em Ciências Socioambientais. Professora Adjunto IV da Faculdade de Serviço Social e do Programa de Pós-Graduação em Serviço Social da Universidade Federal do Pará (UFPa, Belém, Brasil). Guamá, Belém (PA), CEP.: 66075-110. E-mail: <solgayoso@ufpa.br>.
}

DOI 10.22422/temporalis.2019v19n38p180-193

(cc) Br Commons Atribuição 4.0 Internacional (https://creativecommons.org/licenses/by/4.o/deed.pt_BR), que permite copiar e redistribuir o material em qualquer suporte ou formato, bem como adaptar, transformar e criar a partir deste material para qualquer fim, mesmo que comercial. O licenciante não pode revogar estes direitos desde que você respeite os termos da licença.

Temporalis, Brasília (DF), ano 19, n. 38, p. 87-100, jul./dez. 2019. | ISSN 2238-1856 
registradas todos os anos no Brasil. Buzatto (2018) chama atenção para o fato das violações e violência contra os indígenas terem se agravado a partir do ano de 2016, quando são agregados aos atos de violência elementos políticos estruturantes que passam a determinar a relação do Estado brasileiro com os povos originários, ao ponto de subverter determinações Constitucionais vigentes. Nas palavras do autor: "[...] às forças políticoeconômicas e ideológicas anti-indígenas que já estavam instaladas no Palácio do Planalto e na Esplanada dos Ministérios dos governos anteriores, associaram-se grupos ainda mais conservadores, fundamentalistas e financistas [...]" (BUZATTO, 2018, p. 78-79), que passaram a ter um ataque mais sistemático acerca dos direitos indígenas, principalmente, em ações voltadas a liberação de terras sobre as posses dos povos indígenas ao mercado de terras.

Interesses convergentes da bancada ruralista e cerca de quarenta associações de envergadura nacional e regional do agronegócio ficaram expressos no documento Pauta Positiva - Biênio 2016-2017, dentre as quais o Respeito ao marco temporal e às condicionantes do STF, oriundos do caso Raposa Serra do Sol (PET 3388/STF); a Republicação da Portaria 303 da AGU"; a "PEC 215/2000...; e a Revisão das recentes demarcações de áreas indígenas/quilombolas, bem como de desapropriações para fins de reforma agrária... (BUZATTO, 2018, p. 11). Nos últimos anos (2016-2018) o governo Temer consolidou tal pauta reforçando os interesses da bancada ruralista e do agronegócio ao congelar o orçamento pelos próximos vinte anos e realizar cortes orçamentários sucessivos na área das políticas sociais. A exemplo do que acontece com a Fundação Nacional do Índio (Funai) que tendo seu orçamento reduzido ano após ano; o orçamento aprovado para o ano 2017 foi o menor dos últimos dez anos. Tal fato inviabiliza o funcionamento da FUNAI impactando diretamente nos procedimentos para a regularização das Terras Indígenas (TI), na atuação dos conflitos e outras ações necessárias ao reconhecimento e defesa dos povos originários.

Observa-se que essa posição comprometida do Estado brasileiro na violação dos direitos indígenas tem contribuído ainda, para aumento na violência e ódio contra os indígenas. Chama atenção o fato de que, nos últimos anos as ações de ataque e invasão aos territórios indígenas sejam acompanhados de torturas com requintes de crueldade como nos casos dos Tekoha Mbaracay, município de Amambai, em que os anciãos tiveram seus tornozelos fraturados e dos indígenas Gamela em Viana, no interior do Maranhão, em que dois indígenas tiveram suas mãos decepadas durante emboscada sofrida pelo grupo. Em Mato Grosso do Sul, estado com o maior número de casos, o CIMI registrou, no ano de 2015, dez ataques aos acampamentos dos grupos dos povos Guarani e Kaiowá, Ñhandeva e Terena, principalmente em áreas retomadas.

Aliado a isso, identifica também, crescimento da criminalização de lideranças indígenas e de seus aliados na defesa dos seus territórios. Como observa (BUZATTO, 2018) ao lembrar da Comissão Parlamentar de Inquérito instaurada em 2016 para averiguar a atuação da FUNAI/INCRA. Nos chama atenção para o fato da CPI ter sido amplamente usada para criminalizar "[...] líderes indígenas, membros do Ministério Público Federal (MPF) e profissionais da academia, de modo particular da ciência antropológica, além de membros de organizações da sociedade civil que atuam legal e legitimamente em prol dos povos indígenas no Brasil" (BUZATTO, 2018, p. 12).

Os permanentes ataques sofridos pelos indígenas se avolumam e intensificam em decorrência da disputa pelas terras que se encontram sob a posse dos indígenas e ainda

Temporalis, Brasília (DF), ano 19, n. 38, p. 87-100, jul./dez. 2019. | ISSN 2238-1856 
não tiveram seus processos de demarcações concluídos. Cotidianamente são pressionados a abrirem mão de seu território e de sua identidade. Os grupos étnicos que em processo de etnogênese, com os indígenas do baixo Tapajós, bem o sabem da árdua batalha cotidiana pela afirmação de sua identidade indígena e defesa de seu território.

Desde o ano de 2010 a equipe de pesquisa do Projeto Nova Cartografia Social da Amazônia ${ }^{1}$ - núcleo Baixo Amazonas, vem realizando o mapeamento das aldeias e aldeias/comunidades indígenas ${ }^{2}$ localizadas na região do baixo Tapajós, identificando sua localização, elementos identitários, as principais situações de conflitos, demandas e pautas específicas.

Os conflitos vivenciados pelos indígenas do baixo Tapajós não diferem daqueles outros identificados no relatório do CIMI. São casos de ameaças, violências diversas, criminalização e racismo, especialmente racismo institucional. Essas situações específicas têm forte influência na forma de organização do movimento indígena e na definição de estratégias de enfrentamento dos seus antagonistas, especialmente do Estado, cuja morosidade no reconhecimento e na regularização das Terras Indígenas reivindicadas tem aprofundado o processo de disputa e conflito na região.

Sobre a dificuldade do Estado no reconhecimento das terras de povos tradicionais, Almeida (2008) destaca que a Constituição de 1988 incorpora elementos do pluralismo jurídico, significando que o direito produzido pelo Estado não é o único. Este instrumento reconhece o direito à diferença, enunciando o reconhecimento de direitos étnicos. As conquistas e rupturas na Constituição não resultaram na adoção pelo Estado "[...] de uma política étnica e nem tampouco em ações governamentais sistemáticas capazes de reconhecer prontamente os fatores situacionais que influenciam uma consciência étnica" (ALMEIDA, 2008, p. 33). A titulação das terras de indígenas e quilombolas podia ter sido esta ação e ter tido este resultado. Contudo, o autor observa as dificuldades para "[...] implementação de disposições legais desta ordem em sociedades autoritárias e de fundamentos coloniais e escravistas" (ALMEIDA, 2008, p. 33). Após 25 anos de aprovação do Artigo 68 do Ato das Disposições Transitórias conferem-se ações pontuais, dispersas, focalizando fatores étnicos sob cobertura de políticas de educação, saúde, habitação, segurança alimentar. Nesse contexto geral de disputa pela apropriação e uso dos recursos naturais por diferentes agentes sociais é que os indígenas da região do baixo Tapajós vêm se organizando no enfrentamento das situações de violência e conflitos socioambientais e territoriais.

\footnotetext{
1 O Projeto Nova Cartografia Social da Amazônia constitui uma rede de pesquisadores vinculados a Universidades Públicas que, desde o ano de 2005, vem desenvolvendo pesquisas e ações extensionistas voltadas ao fortalecimento da resistência e organização de povos, comunidades tradicionais e movimentos sociais urbanos e rurais. As informações e produções dessa rede estão disponíveis no site http://novacartografiasocial.com/.

${ }^{2}$ As denominações aldeia e aldeia/comunidade correspondem a classificação feita pelos indígenas para diferenciar as localidades em que todas as famílias se autodefiniram indígenas, denominadas de aldeias, daquelas em que moram famílias indígenas e não indígenas, denominadas de aldeia/comunidade.
}

Temporalis, Brasília (DF), ano 19, n. 38, p. 87-100, jul./dez. 2019. | ISSN 2238-1856 


\section{RESISTÊNCIA E MOBILIZAÇÃO DOS POVOS INDÍGENAS DO BAIXO TAPAJÓS PELO RECONHECIMENTO DE SUA IDENTIDADE INDÍGENA.}

A região dos rios Tapajós, Arapiuns e planalto Santareno, localiza-se nos municípios de Santarém, Belterra e parte de Aveiro no estado do Pará. Sua importância decorre da diversidade de uso adotado pelos diferentes agentes sociais, com destaque aos indígenas, que ocupam e/ou habitam historicamente esses municípios. O nome do rio Tapajós vem da denominação dada ao povo Tapajó que ainda habitam porções das margens deste rio. Sua nascente se forma na divisa dos estados do Mato Grosso, Amazonas e Pará, a partir da junção dos rios Juruena e Teles Pires (também denominado de São Manuel), que segue atravessando a parte oeste do estado do Pará até desaguar no rio Amazonas, já o rio Arapiuns nasce na porção noroeste do município de Santarém (Pará) e desagua na foz do rio Tapajós, às margens do rio Amazonas. O nome Arapiuns é uma referência aos povos Arapiuns que ainda habitam as margens deste rio. A região do Planalto Santareno fica no eixo da rodovia Cuiabá-Santarém (BR 163) e está localizada em terras altas que avançam no sentido Sul-Leste.

Nessa região tem se observado, nos últimas 30 anos, um processo crescente de territorialização de povos indígenas, que por meio de diferentes etnias estão se auto afirmando em seus territórios tradicionalmente ocupados. Tais povos indígenas se organizam em associações, conselhos e por territorialidades específicas segundo seus grupos étnicos e os territórios reivindicados. São territorialidades próprias, nas quais a identidade constitui elemento mobilizador do próprio grupo, tanto em torno da luta pelo atendimento de suas reivindicações, quanto na relação com outros agentes sociais. Esse processo está inserido numa dinâmica mais geral dos movimentos sociais no Brasil e, especialmente, na Amazônia, que compreende a multiplicação de novas identidades com base na auto atribuição e organização dos grupos³ (ALMEIDA, 2008; CRUZ, 2014).

Nesse sentido, um crescente movimento de agentes sociais, até então classificados como caboclos ${ }^{4}$, passaram a se auto definir como indígenas e a reivindicar o reconhecimento legal de sua etnia e território. No levantamento realizado em 2015 esse grupo era composto por sessenta e quatro aldeias/comunidades de treze etnias (Arara Vermelha-Tupaiu, Munduruku, Arapiun, Jaraqui, Tapajó, Borari, Munduruku-Apiaká, Tupinambá, MundurukuCara Preta, Maitapu, Yawaretê, Kumaruara, Tapuia) (CADERNO..., 2014).

\footnotetext{
30 processo de mobilização e resistência em defesa do reconhecimento de sua identidade e direito ao território indígena na região do Baixo Tapajós, se agrega a um fenômeno mais amplo que vem ocorrendo na América Latina e no mundo, onde povos considerados extintos reivindicam o reconhecimento de sua existência como povo originário, redefinindo novas relações com o Estado e com a sociedade em geral.

${ }^{4}$ Vaz Filho (2010) sobre o caboclo faz a seguinte observação: "[...] um aspecto que pode chamar a atenção na Amazônia é que essa população regional vizinha aos indígenas, em face da qual eles estariam quase indistintos e com a qual eles eram confundidos, até recentemente, conserva, entre seus costumes e valores, muitos elementos das culturas indígenas pré-colombianas, principalmente de raiz Tupi. Esse fato já foi atestado por todos os estudiosos que trataram da chamada população cabocla na Amazônia. Além do mais, mesmo um viajante comum observa, logo de início, que os traços físicos dos caboclos amazônicos são predominantemente indígenas, ou seja, a população regional ou envolvente apresenta muitos aspectos que podem ser também considerados indígenas. Por isso, na Amazônia, dizer que os povos indígenas emergentes apresentam pouca distintividade frente aos regionais não significa dizer que aqueles apresentem poucos traços indígenas" (VAZ FILHO, 2010, p. 16 ).
}

Temporalis, Brasília (DF), ano 19, n. 38, p. 87-100, jul./dez. 2019. | ISSN 2238-1856 
Para Fredrik Barth, a etnicidade é resultado da interação social e “[...] grupos étnicos são categorias de atribuição e identificação realizadas pelos próprios atores" (BARTH, [1969] 1998, p. 189). De acordo com Barth, o importante é saber como os grupos étnicos são gerados e mantidos, como as diferenças e fronteiras são construídas e seus efeitos no próprio grupo. As identidades indígenas emergem nas comunidades até então caboclas sob a noção de índios resistentes em oposição à noção de índios ressurgidos e à história que nega a existência do indígena misturado e sua permanente presença na região. A noção de índio misturado é reinterpretada como uma longa experiência de negação da cultura indígena contra a qual resistem e se mobilizam na luta pela visibilidade e defesa de seus territórios. Tal processo é denominado na literatura como etnogênese, que segundo Oliveira (1998) inclui "[...] tanto o surgimento de novas identidades quanto a reinvenção de etnias já conhecidas [...]" (OLIVEIRA, 1998, p. 56), que acionam como instrumento político e jurídico a autodeclaração.

A constatação da etnogênese nesta região tem sido observada em trabalhos técnicos publicados pela Fundação Nacional do Índio (FUNAI) e pesquisas acadêmicas (VAZ, 1997a; 2004; IORIS, 2005). Tais autores atribuem as causas da deflagração da etnogênese nessa região, ao avanço da exploração de recursos naturais sobre os territórios tradicionalmente ocupados, da mesma forma, como as políticas de ordenamento territoriais e ambiental promovida por diferentes instâncias do Estado, que por sua vez, têm implantado Projetos de Assentamento Agroextrativistas (PAEx) e Unidades de Conservação (UC) com o argumento de garantir a preservação dos recursos naturais associadas ao desenvolvimento sustentável. No entanto, essa postura, por outro lado, tem sido contraditória, ao mesmo que promove a Concessão de Florestas Públicas e a autorização de pesquisas minerais nas áreas internas e externas dessas áreas de proteção ambiental.

Na região do baixo rios Tapajós e Arapiuns, a etnogênese começou a se expandir, a partir do ano de 1993, quando foi criado o Grupo de Reflexão dos Religiosos Negros e Indígenas (GRENI), com o objetivo de possibilitar aos religiosos e religiosas afrodescendentes e indígenas uma maior conscientização sobre a própria identidade, tendo à frente o frade franciscano, Florencio Vaz, que em seguida protagonizou, em 1997, a criação do Grupo Consciência Indígena (GCl) e, em 2000, o do Conselho Indígena Tapajós Arapiuns (CITA), passando a apoiar e incentivar o processo de etnogênese, além de organizá-los em associações, que incluíram as suas pautas reivindicatórias na agenda política do movimento indígena. Nesse sentido, Vaz Filho (2010) indica que o termo etnogênese é utilizado para denominar também "[...] os processos de emergência social e política dos grupos tradicionalmente submetidos a relações de dominação [...] se refere à constituição de novos grupos étnicos onde antes, aparentemente, só existia a indiferenciação étnica" (VAZ FILHO, 2010, p. 15). Esse autor enfatiza que o processo de etnogênese de povos indígenas na Amazônia deve ser compreendido dentro dos estudos da etnicidade e da identidade étnica.

Hall (2004) em seu estudo sobre a identidade na pós-modernidade chama atenção para uma crise e uma fragmentação das velhas identidades, a valorização de identidades locais e surgimento de novas identidades, sob os efeitos da globalização, que acaba impulsionando novas posições de identificação que conferem à identidade um caráter mais político, posicional, plural e diverso. Mesmo as tradições, mais usualmente pensadas como 
permanência do antigo, podem ser reinventadas, numa releitura e continuidade em relação ao passado histórico (HOBSBAWM; RANGER, 1997).

A emergência de identidades indígenas nessa região está intrinsicamente vinculada à defesa de seus territórios. Oliveira (1998), em sua discussão sobre terra e território, fala de territorialidade e territorialização para diferenciar da distinção usual entre terra e território, argumentando que a "[...] atribuição a uma sociedade de uma base territorial fixa se constitui em um ponto chave para a apreensão das mudanças por que ela passa, isso afetando profundamente o funcionamento das suas instituições e a significação de suas manifestações culturais" (OLIVEIRA, 1998, p. 56). Nesse sentido, para esse autor, a noção de territorialização é definida como um processo de reorganização social. O sentido de processo de territorialização é o de movimento pelo qual um objeto político-administrativo como comunidades indígenas se transformam em uma coletividade organizada, "formulando uma identidade própria".

A adoção do conceito de processo de territorialização permite-nos alcançar o seu entendimento a partir dos sistemas de relação sociais que constroem territorialidades. Almeida (2006) afirma que a territorialidade funciona como fator de "[...] identificação, defesa e força [...]" (ALMEIDA, 2006, p. 24), encontrando-se também associada a uma identidade especifica. $O$ embate entre identidades especificas e suas territorialidades ${ }^{6}$ pode ser observado no processo de mobilização dos povos indígenas na luta por seu território.

Nessa região a dimensão política dos processos de territorialização dos indígenas relaciona-se principalmente com a apropriação de território pelos grupos étnicos e pela defesa de um modo de vida que conflita com as normativas das unidades de conservação e com as atividades econômicas de exploração e devastação dos recursos naturais. Podemse identificar três momentos importantes desse processo de organização: o primeiro quando da mobilização das comunidades ribeirinhas localizadas nos rios Tapajós e Arapiuns pela criação da RESEX Tapajós-Arapiuns, como forma de proteção de seus territórios ameaçados pela presença de madeireiras e pequenas mineradoras na região. Ribeirinhos com apoio do Sindicato dos Trabalhadores Rurais (STR), a Igreja Católica e outras ONGs, formaram um Grupo de Trabalho (GT), que passou a coordenar as atividades do movimento pela Resex, contando ainda, com o apoio do Ministério Público Federal (MPF). No início de 1997, após muitos encontros intercomunitários, mais de 60 comunidades solicitaram oficialmente a criação da Resex Tapajós-Arapiuns, e realizaram várias mobilizações para pressionar o Governo Federal a atendê-los (VAZ FILHO, 2010). Foi nesse momento de mobilização que foi fundado o GCl. Em fins de 1988 a Resex Tapajós-Arapiuns foi criada e significou uma grande conquista para as comunidades locais.

Foi nesse contexto que o movimento indígena passou a se organizar nessa região, tendo como momento marcante para o seu desencadeamento crescente o falecimento do pajé

\footnotetext{
5 “Por 'tradição inventada' entende-se um conjunto de práticas, normalmente reguladas por regras tácita ou abertamente aceitas; tais práticas de natureza ritual ou simbólica, visam inculcar certos valores e normas de comportamento através da repetição, o que implica, automaticamente, uma continuidade em relação ao passado" (HOBSBAWM; RANGER, 1997, p. 9).

${ }^{6}$ Almeida qualifica o termo territorialidade com - "[...] territorialidade específica [...]", para "[...] nomear as delimitações físicas de determinadas unidades sociais que compõem os meandros de territórios etnicamente configurados" (ALMEIDA, 2006, p. 25).
}

Temporalis, Brasília (DF), ano 19, n. 38, p. 87-100, jul./dez. 2019. | ISSN 2238-1856 


\section{tempordilis}

Laurelino em 1998, morador da Comunidade de Takuara localizada na Flona Tapajós. Segundo Edviges loris (2005; 2009), o movimento indígena na Flona Tapajós surgiu como reação à identidade genérica de população tradicional imposta pela ação governamental, cuja definição baseava-se em critérios ecológicos e não socioculturais. Segundo a autora, não foi apenas para permanecer em suas terras que as comunidades indígenas se mobilizaram, mas também para exercer um particular modo de vida que as imposições da categoria população tradicional negava. Após a decisão da comunidade de Takaura outras comunidades passaram a se interessar a aderir ao processo de emergência étnica. Foi então realizado o I Encontro dos Povos Indígenas do rio Tapajós, nos dias 31/12/1999 e 01/01/2000, na comunidade de Jauarituba. O objetivo principal foi o de celebrar os 500 anos de resistência indígena e promover o resgate da história, identidade e tradições indígenas locais. Desse encontro participaram cento e cinquenta representantes de dez comunidades, que debateram, principalmente, sobre os direitos indígenas, contando com apoio de Euclides Macuxi, representante da Coordenação das Organizações Indígenas da Amazônia Brasileira (COIAB) e com o representante do Conselho Indigenista Missionário (CIMI). Na oportunidade os presentes foram convidados a participarem da Marcha Indígena dos 500 Anos, que passaria em Santarém em abril de 2000, a caminho de Coroa Vermelha (BA) (VAZ FILHO, 2010, p. 37-40).

$\mathrm{Na}$ volta da Bahia as lideranças indígenas, consciente da necessidade de organizar as comunidades que estavam se auto identificando como indígenas, criam, em maio de 2000, o CITA. Constituindo-se como principal representação política de mobilização indígena do Baixo Tapajós que passou, então, a organizar juridicamente as ações no plano dos direitos indígenas diante a FUNAI e de outros órgãos públicos. Como um desdobramento da emergência política dos indígenas, o CITA e o GCl abriram seu escritório em Santarém em 18 de março de 2001 (VAZ FILHO, 2010).

Ioris (2009) sinaliza alguns avanços na perspectiva dos direitos territoriais indígenas, visto que a FUNAI tem se feito presente desde 1998, colhendo denúncias de violência contra indígenas nas regiões de conflito fundiário, criando, para tanto, em 2001 o primeiro Grupo de Trabalho Técnico (GT) que apresentou resultados técnicos no tocante aos estudos preliminares para a identificação e delimitação de terras indígenas na região. Até o ano de 2015 foram realizados e publicados quatro estudos antropológicos: Terra Indígena ( $\mathrm{TI}$ ) Bragança -Marituba e Munduruku Takuara (DOU N 208 de 30/10/2009); TI Maró (DOU Nº 195 de 10/10/2011); e TI Cobra Grande (DOU No 186 de 29/09/2015).

O processo de mobilização indígena no Baixo Tapajós é expressivo de manifestações sucessivas de construção de uma existência coletiva, que se dá de forma dinâmica e aponta para um crescimento dessas identidades políticas objetivadas em movimentos sociais. Têm-se uma nova configuração étnica na região, em que suas expressões se traduzem pelas unidades de mobilização que evidenciam a consciência de sua identidade indígena. Assim sua existência coletiva, manifesta em rituais, encontros, reuniões, assembleias, indumentária, reivindicações ao acesso dos direitos indígenas, traduziriam essa etnicidade. A etnicidade se traduz pelo modo de representação, de ação, de organização estratégica, na medida em que tais sujeitos sociais utilizam-se de identidades étnicas para se posicionarem frente aos outros. As relações associativas e os territórios, unidades de mobilização, são acionados pelo grupo sempre que for necessário se posicionar frente ao

Temporalis, Brasília (DF), ano 19, n. 38, p. 87-100, jul./dez. 2019. | ISSN 2238-1856 
outro. Para fora tais unidades de mobilização se apresentam como homogêneas. Para dentro são heterogêneas e guardam especificidades que lhes são próprias.

\title{
VIOLÊNCIA, DISCRIMINAÇÃO, RACISMO E CONFLITOS ENVOLVENDO OS POVOS INDÍGENAS DO BAIXO TAPAJÓS
}

Esse amplo movimento de autodeterminação e reivindicações de direitos, protagonizados por esses 13 povos indígenas é percebido pela sociedade regional de maneira bastante complexa, na medida em que tal sociedade já havia assimilado que os povos indígenas nessa região já haviam sido extintos. São constantes as afirmações de que se trata de falsos índios - sujeitos que tentam se passar por índios para obter supostos benefícios, principalmente o de apropriar-se de terra alheia?.

Nesse contexto, diversas situações de intolerância, violência e racismo étnico/institucional são praticadas por não índios contra os indígenas que habitam a região. O registro das denúncias protocoladas no Ministério Público Federal (MPF) em Santarém, demonstram diversas violações de direitos, principalmente: o direito ao seu território/terra, o acesso à educação e acesso à assistência à saúde; somam-se a estas as condutas de desrespeito à cultura e a tradição indígena e aos direitos assegurados pela legislação brasileira. Como comprobatório desses fatos podemos listar os diversos procedimentos instaurados pelo MPF ao longo dos anos:

\begin{abstract}
- Em 2011, 2012 e 2013, o professor Raimundo Enoque Monteiro Cardoso, cacique da Aldeia Vila Franca, noticiou a prática de condutas discriminatórias ocorridas na Escola Indígena Nossa Senhora da Assunção. Com base em suas declarações, foram instaurados os procedimentos administrativos $n^{\circ} 1.23 .002 .000664 / 2011-60$ e 1.23.002.000544/2012-43, posteriormente remetidos à Polícia Federal para a instauração de inquéritos policiais;

- No ano de 2013, indígenas da Aldeia Aminã informaram a prática de atos de discriminação e de preconceito cultural praticado por servidor do Instituto Chico Mendes de Conservação de Biodiversidade;

- Em 2014, o Conselho Indígena Tapajós e Arapiuns (CITA) remeteu documento ao MPF no qual informa a queimada de uma maloca instalada na aldeia Cabeceira do Amorim por comunitários que estariam, ainda, ameaçando lideranças indígenas do local. Os fatos narrados nesta representação estão sendo investigados na Notícia de Fato no 1.23.002.000081/2014-81 (BRASL, 2014b, p. 3-4).
\end{abstract}

Dentre as medidas adotas pelo MPF em resposta às denúncias registradas pelo indígenas e defesa de seus direitos, destaca-se: i) AÇÃO CIVIL PÚBLICA contra a União, Estado do Pará e Município de Santarém, visando condenar a União, o Estado do Pará e o Município de Santarém, à implementação de medidas educacionais aptas a fazer cessar os atos de discriminação sofridos por indígenas na área deste Município, datada de 20 de fevereiro de 2014 (BRASIL, 2014b); ii) AÇÃO CIVIL PÚBLICA contra a Fundação Nacional do Índio (FUNAI), objetivando a publicação imediata do relatório antropológico da Terra Indígena Maró no Diário Oficial da União, datada de 09 de março de 2010 (BRASIL, 2010); iii) AÇÃO CIVIL PÚBLICA contra a UNIÃO, afim de garantir a prestação do serviço público de saúde aos 13 povos indígenas que vivem na região do baixo rio Tapajós, rios Arapiuns e Planalto Santareno, assim como também visa garantir a prestação de saúde diferenciada aos indígenas que vivam nos centros urbanos, datada de 10 de dezembro de 2015 (BRASIL, 2015).

\footnotetext{
7 Como exemplo ver sentença Justiça Federal de Primeiro Grau no Pará: Segunda Vara da Subseção de Santarém. Sentença dos Processos: 2010.39.02.000249-0 e 2091-80.2010.4.01.3902 (BRASIL, 2016).
} 
As ações impetradas pelo MPF têm trazido resultados positivos importantes no fortalecimento da organização dos indígenas e da garantia de seus direitos, mesmo que levem anos para serem de fato concretizadas. No caso da primeira ação (BRASIL, 2014) que objetiva garantir ações por parte da União, Estado do Pará e município de Santarém, somente em 25 de outubro de 2016 foi assinado acordo judicial entre as partes envolvidas, em audiência de conciliação judicial, que se comprometem a: realizar anualmente semana de combate ao preconceito contra os indígenas; elaborar cartilhas de conscientização sobre as culturas indígenas; campanhas de conscientização na mídia local; ações voltadas à implantação permanente de ensino da cultura indígena na rede local de educação, dente outros.

Em 10 de outubro de 2011, tivemos a publicação do relatório antropológico da TI Maró publicado no Diário Oficial da União. Contudo, até o ano de 2018 a TI Maró ainda não foi regularizada, mantendo-se os povos indígenas Borari e Arapiuns das aldeias Novo Lugar, Cachoeira do Maró e São José III, localizadas na margem esquerda do rio Maró, em situação de vulnerabilidade territorial e sob constantes ameaças de madeireiros e grileiros que avançam na região para exploração dos recursos naturais. A TI Maró localiza-se na Gleba Estadual Nova Olinda, local de intenso conflito fundiário, envolvendo os indígenas, populações tradicionais, madeireiros, sojicultores e grileiros de terra, envolvidos numa complexa rede de disputa e agenciamento de terras, com importante participação do Estado no ordenamento territorial e fomento do conflito ${ }^{8}$, conforme o relato do Segundo Cacique da Comunidade Indígena Novo Lugar feito na reunião do Grupo de Trabalho sobre a Política Indigenista do Estado do Pará9 transcrito em COSTA (2012).

\begin{abstract}
A Gleba Nova Olinda é uma área do Estado. E a própria Secretaria do Meio Ambiente, a SEMA, jogou as pessoas de outro estado lá (refere-se aos permutados). Tem projeto, mas não tem fiscalização desses projetos. Da Gleba sai muita madeira. Antes nunca tinha sido mexido por ninguém. A SEMA não faz a fiscalização, depois faz o relatório e diz que está tudo legal. Na reunião ontem com a SEMA nos perguntávamos o que ela entendia da questão ambiental, da ameaça ao mundo social. A própria SEMA aprovou planos de manejo dentro do pedido do território indígena por que não temos a documentação (refere-se à área pleiteada pelas comunidades indígenas para demarcação de suas terras). Eles estão negando um direito. Têm várias lideranças ameaçadas, sofrendo, eu sou uma delas. [...] Em outubro do ano passado foi feita uma manifestação para chamar a atenção do Governo do Estado. Nosso pedido era para não dar mais liberação para o plano de manejo. Criamos o 'Movimento em defesa da vida e da cultura do Arapiuns'. Passamos um mês acampados e o Estado não deu nenhuma posição. As respostas que nós esperávamos foram todas negativas. Houve a queima da madeira. Hoje várias pessoas do movimento receberam liminar, eu sou uma; inclusive com mandado de prisão. [...] (COSTA, 2012. p. 168).
\end{abstract}

Em decorrência dos conflitos e a não ação do Estado no sentido de evitar a retirada de madeiras na Gleba, levou os indígenas, as populações locais e o sindicato dos Trabalhadores e Trabalhadoras Rurais de Santarém a organizar um longo protesto no rio Maró, com acampamento e bloqueio o rio, e retenção de balsa carreada de madeira. Tal

\footnotetext{
${ }^{8}$ Sobre ver Catete (2016).

9 Tal reunião aconteceu no período de 09 a 11 de fevereiro de 2010, na sede da Secretaria de Turismo de Santarém. Coordenava os trabalhos a Secretaria de Justiça de Direitos Humanos do Estado do Pará. Na reunião estavam presentes várias lideranças indígenas da região do Baixo amazonas e Oeste do Pará. O relato aqui exposto foi feito no primeiro dia da reunião, em que tive a oportunidade de acompanhar pessoalmente.
}

Temporalis, Brasília (DF), ano 19, n. 38, p. 87-100, jul./dez. 2019. | ISSN 2238-1856 
ação foi utilizada para outra pratica de violência contra os indígenas - a criminalização. A manifestação realizada pelos povos indígenas e comunidades de ribeirinhos em outubro de 2009, que culminou na queima da madeira retida pelo movimento, resultou em um processo judicial com indiciamento de lideranças indígenas, do presidente e vicepresidente do STTR de Santarém, e de assessores vinculados às entidades que prestam apoio as comunidades residentes na Gleba. O processo identificado como de criminalização dos movimentos sociais transformou em crimes as ações, atos e manifestações públicas de reivindicação de direitos ${ }^{10}$.

Costa (2012) entende que o fenômeno da criminalização dos movimentos sociais, precisa ser entendido como um dispositivo utilizado pelos agentes envolvidos no mercado de terras para liberação de áreas. A autora toma como referência a compreensão do "dispositivo" no sentido utilizado por Foucault (2000), que considera um conjunto heterogêneo "[...] de discursos, instituições, de organizações arquitetônicas, decisões regulamentares, leis, medidas administrativas, enunciados científicos, proposições filosóficas, morais, filantrópicas [...]" (FOUCAULT, 2000, p. 244), que compõem a dinâmica do mercado de terras. O dispositivo é a "[...] rede que se pode estabelecer entre estes elementos" (COSTA, 2012, p. 171). A estratégia de criminalizar as principais lideranças dos movimentos tem como objetivo impedir o crescimento de uma força política com capacidade de questionar e colocar em cheque as convenções (leis, normativas legais e administrativas) e posicionamentos políticos oficiais sobre a propriedade privada da terra. Trata-se de uma correlação de forças, de um jogo de poder que pressupõe a manipulação, a intervenção racional e organizada nessas relações de forças.

Dentre as lideranças criminalizadas encontra-se o cacique da Aldeia Novo Lugar Dadá Borari, acusado de prática de crime de falsidade ideológica e falsa identidade, contestando a reivindicação dos remanescentes dos povos indígena Borari e Arapiuns, ferindo a Convenção 169, da qual o Brasil é signatário. A criminalização dos movimentos tem sido um dispositivo recorrente na estratégia dos agentes dominantes para a imposição de um saber e um entendimento sobre os direitos de propriedade da terra e uso dos recursos naturais. E como refere Foucault, o dispositivo é uma estratégia de relações de força sustentando tipos de saber e sendo sustentadas por eles.

Outro exemplo de criminalização de lideranças indígena ocorreu por ocasião do protesto organizado pelo movimento indígena no dia 9 de agosto de 2016 , quando mais de sessenta indígenas de treze etnias representadas pelo Conselho Indígena Tapajós e Arapiuns (CITA) ocuparam a sede da Secretaria Especial de Saúde Indígena (SESAI- Pólo Basec Santarém) com o objetivo de reivindicar o cumprimento da decisão liminar proferida pela Justiça Federal de Santarém no bojo da Ação Civil Pública impetrada pelo MPF contra a União em,

\footnotetext{
${ }^{10}$ Originalmente a Criminalização ou judicialização dos atos (protestos, manifestações) dos movimentos sociais foi identificada por Boaventura dos Santos (2009), que observou a existências nos países latinoamericanos de uma contrarrevolução jurídica: “[...] uma forma de ativismo judiciário conservador que consiste em neutralizar, por via judicial, muito dos avanços democráticos que foram conquistados ao longo das duas últimas décadas pela via política, quase sempre a partir de novas Constituições. Como o sistema judicial é reativo, é necessário que alguma entidade, individual ou coletiva, decida mobilizá-lo. E assim tem vindo a acontecer porque consideram, não sem razão, que o Poder Judiciário tende a ser conservador" (SANTOS, 2009, não paginado). Dessa forma o que se tem observado é um processo de crescimento do que ao autor denominou de criminalização dos movimentos sociais, em que seus antagonistas acionam o poder judiciário como forma de fazer prevalecer seus próprios interesses.
}

Temporalis, Brasília (DF), ano 19, n. 38, p. 87-100, jul./dez. 2019. | ISSN 2238-1856 


\section{tempordilis}

objetivava garantir a prestação do serviço público de saúde. Durante o protesto a liderança indígena Adenilson Alves de Souza (Poró Borari), indígena da etnia Borari, Terra Indígena Maró, foi detido por suposta prática do crime previsto no artigo 148 do Código Penal (cárcere privado). Dentre os mais de sessenta indígenas participando do protesto apenas essa liderança foi detida. Vale ressaltar, que Poró Borari é irmão de Dadá Borari, cacique da Aldeia Novo Lugar, também criminalizado pela suas ações de protestos e reivindicações na defesa dos direitos dos povos indígenas e populações tradicionais moradoras da região. Fica claro o direcionamento da criminalização especialmente aos indígenas da TI Maró, ícone da luta, referência e inspiração na organização do movimento indígena na região. Após ser levado pela Polícia Federal para a delegacia, Poró Borari participou no dia seguinte de uma audiência de custódia na qual a Justiça concedeu liberdade provisória e proferiu medida cautelar que determina que Poró deverá frequentar a justiça a cada quatro meses. A audiência foi acompanhada pelo MPF que considerou a prisão ilegal. Em 06 de dezembro de 2016 o MPF entrou com pedido de arquivamento do inquérito policial.

O protesto com a ocupação da sede da SESAI em Santarém conseguiu mobilizar a União para cumprir a decisão judicial proferida em dezembro de 2015, uma vitória como afirmar Luana Kumaruara: "[...] a gente sempre viu uma grande resistência de fazer inclusão dos indígenas do Baixo Tapajós nesse atendimento de saúde [...]. Ocupar foi a forma que vemos de alcançar o avanço dessas demandas. A proposta inicial era levar 15 lideranças à Brasília, mas como houve resistência pedimos que eles viessem até aqui" (SESAI..., 2016). Em 19 de setembro de 2016, em reunião em Santarém, entre as instituições públicas e representações do movimento indígena, o Ministério da Saúde, por meio da Secretaria Especial de Saúde Indígena (Sesai), comprometeu-se com o Ministério Público Federal (MPF) e com os indígenas a buscar aumento de verbas para garantir que a ampliação do atendimento à saúde de mais 13 povos indígenas da região.

Outras situações de conflitos e violência sofrida pelos indígenas têm sido relatadas ao longo dos anos durante as pesquisas para elaboração da cartografia social, tais como: conflitos de pesca pela invasão de suas áreas de pesca e a prática da pesca e caça predatória; a discriminação étnico/racial pelos não indígenas está presente nas aldeias/comunidades em que há presença de famílias não indígenas, o que ocasiona principalmente conflitos nas escolas; conflito com sojicultores no Planalto Santareno por causa do desmatamento e assoreamento dos igarapés, uso de agrotóxicos; registra-se ainda a discriminação sofrida pelos alunos indígenas nas universidades, fato que tem sido denunciado amplamente pelo Diretório dos Estudantes Indígenas (DAIN) e que tem se constituído em pauta do movimento indígena.

Outro conflito importante de ser mencionado trata-se da relação estabelecida entre o Instituto Chico Mendes de Conservação da Biodiversidade (ICMBio) e os indígenas residentes na RESEX Tapajós Arapiuns. É comum os indígenas relatarem as dificuldades em conseguir manter a reprodução social da unidade familiar, se cumprirem rigorosamente as determinações do Instituto com relação ao uso dos recursos florestais. Isso tem gerado inúmeras situações classificadas pelos indígenas como atos discriminatórios. 


\section{CONSIDERAÇÕES FINAIS}

Os conflitos, violência e discriminação sofridos pelos indígenas do Baixo Tapajós, como já mencionado, não diferem daqueles sofridos pelo muitos outros povos indígenas residentes em nosso país. As situações identificadas dizem respeito ao acesso aos recursos ofertados pela natureza. Ameaças de morte são constantes ao longo dos rios Tapajós, Arapiuns e Maró, tendo como principal causa a disputa pela exploração madeireira. São atos de violação permanente de seus direitos ao território, de acesso às políticas de saúde, educação, assistência social, regularização fundiária e valorização étnico-cultural. Tais atos, como lembra Almeida, são próprios das sociedades de passado colonial e escravista.

Os conflitos e violação dos direitos dos povos indígenas do Baixo Tapajós têm sido historicamente construídos sob os auspícios do discurso do desenvolvimento, concretizado na implantação dos chamados grandes projetos, do crescimento do agronegócio de grãos e pecuária, da exploração madeireira, do extrativismo mineral, das grandes obras de infraestrutura e logística, dentre outros.

\section{REFERÊNCIAS}

ALMEIDA, A. W. B. de. Terras de Quilombos, Terras Indígenas, "Babaçuais Livres", "Castanhais do Povo", Faxinais e Fundos de Pasto: Terras tradicionalmente ocupadas. Manaus: PPGSCA-UFAM, 2006.

ALMEIDA, A. W. B. de. Terras tradicionalmente ocupadas: terra de quilombos, terras indígenas, "Babaçuais Livre", "Castanhais do Povo", Faxinais e Fundos de Pasto. 2. ed. Manaus: editora da Universidade do Amazonas, 2008.

BARTH, Fredrik. Grupos étnicos e suas fronteiras. In: POUTIGNAT, Philippe; STREIFFFENART, Jocelyne. Teorias da etnicidade; seguido de Grupos Étnicos e suas Fronteiras de Fredrik Barth. 2. ed. São Paulo: UNESP, 1998.

BRASIL. Justiça Federal de Primeiro Grau no Pará: Segunda Vara da Subseção de Santarém. Sentença dos Processos: 2010.39.02.000249-0 e 2091-80.2010.4.01.3902 (ações civis públicas). $1^{\circ}$ Autor: Ministério Público Federal. $2^{\circ}$ Autor: Associação Intercomunitária de Trabalhadores Agroextrativistas de Prainha e Vista Alegre do Rio Maró e outros. Réus: Fundação Nacional do Índio e União. Juiz: José Airton de Aguiar Portela. Santarém, 26 nov. 2014a. Disponível em:

http://www.prpa.mpf.mp.br/news/2015/arquivos/entenca_TI_Maro.pdf. Acesso em: 27 jul. 2016.

BRASIL. Ministério Público Federal. Ação Civil Pública -n² 2096-29.2015 •4.01.3902. Brasília (DF), 2015.

BRASIL. Ministério Público Federal. Ação Civil Pública - nº 1.23.002.000043/2014-29. Brasília (DF), 2014b.

BRASIL. Ministério Público Federal. Ação Civil Pública. - nº 1.23.002.000587/2009-23. Brasília (DF), 2010.

Temporalis, Brasília (DF), ano 19, n. 38, p. 87-100, jul./dez. 2019. | ISSN 2238-1856 
BUZATTO, Cleber César. Integracionismo à vista: a violência contra os indígenas e o golpismo no Brasil. In: CIMI. Relatorio violência contra os povos indígenas no Brasil: dados de 2016. Publicado em 2018.

CADERNO Nova Cartografia e Mapeamento sociais: resistência e mobilização dos Povos Indígenas do Baixo Tapajós, 2014 .

CATETE, Vania Lucia Lemos. Mercado de terras, apropriação e exploração dos recursos naturais na Amazônia: o caso da Gleba Nova Olinda no Estado do Pará. 2016. Dissertação (Mestrado)-Universidade Federal do Pará, Programa de Pós-Graduação em Serviço Social, Belém, 2016.

COSTA, S. M. G. da. Grãos na floresta: estratégia expansionista do agronegócio na Amazônia. Tese (Doutorado)-Universidade Federal do Pará, Núcleo de Altos Estudos Amazônicos, Programa de Pós-Graduação em Desenvolvimento Sustentável do Trópico Úmido, Belém, 2012.

CRUZ, V. C. Movimentos sociais, identidades coletivas e lutas pelo direito ao território na Amazônia. In: Onildo Araújo da Silva; Edinuzia Moreia Carneiro Santos; Agripino Souza Coelho Neto. (Org.). Identidade , Território e Resistência. 1.ed. Rio de Janeiro:

Consequência, 2014, v. 1, p. 37-72.

FOUCAULT, M. Microfísica do poder. 15. ed. Rio de Janeiro: Grall, 2000.

SESAI de Brasília vem a Santarém ouvir demandas de indígenas. G1, Santarém, 17 ago. 2016. Disponível em: http://g1.globo.com/pa/santarem-regiao/noticia/2016/08/sesai-debrasilia-vem-santarem-ouvir-demandas-de-indigenas.html. Acesso em: 20 nov. 2018.

HALL, S. Identidade cultural na pós-modernidade. Rio de Janeiro: DP\&A, 2004.

HOBSBAWM, E.; RANGER, T. As invenção das traduções. Tradução de Celina Cardim Cavalcanti. Rio de Janeiro: Paz e Terra,1997.

IORIS, E. M. Identidades negadas, identidades construídas: processos identitários e conflitos territoriais na Amazônia. In Revista ILHA. V. 11 -número 2, p. 219-264, 2009. Disponível em: http://www.periodicos.ufsc.br/index.php/ilha/article/view/19411/17796. Acesso em: 20 nov. 2018.

IORIS, Edviges. A Forest of Disputes: Struggles Over Spaces, Resources and Social Identities in Amazônia. 2005. Tese (Doutorado em Antropologia)-University of Florida, Gainesville - Fl, 2005.

OLIVEIRA, J. P. A etnologia dos "índios misturados", situação colonial territorialização e fluxos culturais. Mana, v. 4, n. 1, p. 47-77, 1998. Disponível em:

http://www.scielo.br/scielo.php?script=sci_arttext\&pid=S0104-93131998000100003. Acesso em: 20 nov. 2018. 
SANTOS, B. de S. A contrarrevolução jurídica. Jornal Folha de São Paulo, São Paulo, 4 dez. 2009, Coluna Opinião. Disponível em:

https://www1.folha.uol.com.br/fsp/opiniao/fz0412200909.htm. Acesso em: 20 nov. 2018.

VAZ FILHO, Florêncio Almeida. A emergência étnica de povos indígenas no Baixo Rio Tapajós, Amazônia. 2010. Tese (Doutorado em Ciências Sociais)- Programa de PósGraduação em Ciências Sociais, Universidade Federal da Bahia, Salvador, 2010. 